\title{
Palabras e Ideas: "Patria" y "Nación" en el Virreinato del Perú*
}

A comienzos del siglo XIX una serie de estados independientes reemplazó en América al imperio español de Indias. Puesto que la disolución de este imperio (salvo las posesiones isleñas) y la aparición en su lugar de nuevas entidades políticas fue rápida (1810-1824), cabrĭa suponer que el proceso de previa auto-identificación, diferenciación y separación con respecto de lo que había sido una común identidad imperial se hubiera incubado durante un periodo más largo.

En efecto, don José Ortega y Gasset postulaba que desde las más tempranas fechas de la conquista y la colonización los españoles que vinieron al Nuevo Mundo empezaron a diferenciarse de sus coterráneos de la Península. ${ }^{1} \mathrm{El}$ apotegma orteguiano "yo soy yo y mi circunstancia" hallaba asî su verificación americana, dado que la circunstancia del español en México o en el Perú no era, a partir del siglo XVI, la circunstancia del español en Toledo o en Sevilla o aun en los dominios de Italia y Flandes; y cierto es que ya desde los días de la primera generación de españoles nacidos en Indias poseemos documentos expresivos de su sentirse no ser como los españoles nacidos en España. ${ }^{2}$ El tema de la dicotomía criollo-peninsular ha sido, sin embargo, muy trabajado y me parece superfluo volver sobre el asunto.

Por otra parte se me ocurre que pudiera ser útil la busca de prodromos de la aparición de una identidad o unas identidades diferenciales americanas por medio del examen de la expresión verbal en las colonias de los conceptos de Patria y nación, palabras y conceptos que han ido asociándose a las personalidades colectivas base de la existencia de los estados políticos independientes modernos. Para ponerle puertas al campo, en el presente estudio me limito a 
examinar algunos materiales paradigmáticos procedentes de una sola región americana, el virreinato del Perú, antes de que su independencia se perfeccionara en la batalla de Ayacucho el 9 de diciembre de 1824 .

He escogido patria y nación porque son palabras-clave de la era del nacionalismo. Esas palabras, además, son ambiguas o, mejor dicho, susceptibles de varios significados. El espléndido Oxford English Dictionary, por ejemplo, da cuatro definiciones de patria y no menos de ocho acepciones de nación. ${ }^{3}$ La última edición del Diccionario de la Española es, en los artǐculos pertinentes, menos detallado y lo es menos también que el llamado de Autoridades, primer diccionario de la propia Academia, que por lo menos daba dos artículos a patria y tres a nación. ${ }^{4}$ Sea ello como fuere, echemos ahora un vistazo sobre esas palabras en escritos del virreinato peruano, anteriores a la Independencia.

El primer gran escritor nacido en América, el Inca Garcilaso de la Vega (1539-1616), hijo de un capitán español y una princesa india, decỉa en el "Prohemio al lector" de sus Comentarios reales (1609) que aunque había habido españoles curiosos que escribieron sobre las repúblicas del Nuevo Mundo, él "como natural de la ciudad del Cuzco ... forzado del amor natural de la patria," había emprendido la labor de escribir su obra. Claramente en este texto patria se refiere a la ciudad imperial, igual que ocurre en otros pasajes del mismo autor, por ejemplo, "residiendo mi madre en el Cuzco, su patria" (I, xiv), sentido entonces normal en castellano. A fines del periodo colonial que aquí nos ocupa, hallamos esa palabra con igual significado bajo la pluma de Manuel Lorenzo de Vidaurre (1773-1841), quien en su Plan del Perú, redactado en 1810, escribia, "En Lima, mi patria..., 5

En el castellano de los siglos XVI y XVII patria fue usada también, a veces, no sólo para designar el pueblo o ciudad de nacimiento sino toda la provincia, paǐs o reino en que se habǐa nacido, siguiendo en esto la tradición del latîn clásico. ${ }^{6}$ En el Perú, según lo ha señalado José Durand, el Inca Garcilaso decía, "el primero que llevó trigo a mi patria (yo llamo así a todo el imperio que fue de los Incas) fue una señora noble, llamada María de Escobar..." (CR, IX, xxiv). ${ }^{7}$ Ahora bien, el imperio de los incas se extendia desde lo que es ahora el Ecuador hasta Bolivia, el norte de la Argentina y Chile; pero como el mismo Garcilaso explica, los indios "en su lenguaje no tuvieron nombre genérico para nombrar en junto los reinos y provincias que 
sus reyes naturales señorearon ... nombre propio que significase todo el reino junto, no le tuvieron; llamábanle Tauantin suyu, que quiere decir las cuatro partes del mundo" (CR, I, v). No tuvieron, pues, nada como los nombres de España, Italia o Francia. Es más, el nombre Perú, que los indios no tomaban en la boca ( $C R$, ibid.), pero que Garcilaso emplea constantemente, era el resultado de una confusión lingüistica de los españoles. Garcilaso, pues, que llama con el nombre Perú a todo lo que fue el imperio de los Incas, declara que todo ese territorio es su patria. A lo que parece es el primer escritor americano en hacerlo. Durand ve en esa frase la primera intuición de una patria peruana. Puede uno preguntarse, sin embargo, si Garcilaso, orgulloso de pertenecer por parte de madre a la familia real inca y cuyos Comentarios registran la versión cuzqueña o imperial de su historia, al reclamar todo el imperio como su patria no daba a los reinos y provincias una común identidad unitaria que no habian verdaderamente obtenido, del mismo modo que no habían alcanzado a tener un solo nombre genérico que también él suplía al emplear el término Perú usado por su padre y los demás españoles. De todos modos, su frase es tantalizadora y creo que cabe dentro de los límites de la prudencia suponer que Garcilaso (cualquiera que la realidad en el pasado indio hubiera sido) proyectaba hacia las generaciones venideras, según sugiere Durand, la visión de una patria imperial o una patria peruana en el sentido de país que el término empezaba a poseer en bocas europeas.

Por otra parte, un amigo y defensor de los indios, un criollo, el cura de Ticsán (corregimiento de Cuenca), Francisco Rodríguez Fernández, todavĭa hablaba a fines del siglo XVII de las patrias de los indios, patrias en plural, en un sermón predicado el tercer viernes de la Cuaresma de 1679 al obispo, capítulo catedralicio y cabildo municipal de Quito: “¿No están en sus patrias?" preguntaba al condenar las exacciones a que estaban sometidos los naturales.

El uso de patria para indicar el pueblo o ciudad de nacimiento continuó siendo el prevalente en el Perú. Por ejemplo, el polígrafo don Pedro de Peralta Barnuevo y Rocha (1663-1743), en su Lima inexpugnable (1740), tratado en el que proponia la construcción de una ciudadela para defender aquella capital contra un posible ataque inglés, declaraba haber preparado el proyecto y el libro por su "obligación y celo sobre la mejor, más segura y más perpetua Defensa de la Patria"; 9 en este caso, la ciudad de los Reyes.

Aunque tal sentido y significado sigue siendo el más frecuente en el Perú virreinal, hacia la mitad del siglo XVIII otra acepción de la palabra comienza a aparecer en los textos: el uso, el significado, la 
idea de que América, la totalidad de la América española, es la patria de los nacidos en ella. Por ejemplo, José Eusebio de Llano Zapata $(+1780)$, sabio limeño del Siglo de las Luces, en sus Memorias histórico-criticas-apologéticas de la América meridional (1761), empleaba expresiones como las siguientes: "Quisiera que nuestros españoles americanos...hicieran cada día nuevos descubrimientos... [porque es lástima] que cuando otros velan por ser el ornamento de la patria, los nuestros duerman con menoscabo de la suya." 10 La patria de "nuestros españoles americanos" no es, pues, en este texto ni la ciudad nativa ni el reino americano en que se habia nacido sino América, la América española. Resulta poco probable que en el citado texto patria sea España o aún España con sus dominios porque entonces Llano Zapata hubiera escrito "nuestros españoles" y no la frase limitativa "nuestros españoles americanos." La patria americana que Llano parece postular se hallará más taxativamente propugnada treinta años más tarde, y con significado explïcitamente político, por el Abate Viscardo, aunque no es probable que éste conociera la obra de aquél, por entonces inédita, circulada sólo en manuscritos.

La idea setecentista de la América española como una unidad y, para un americano, como una sola patria, aparece por las fechas de la introducción en las colonias de las ideas y las reformas promulgadas por los reyes de la casa de Borbón y sus ministros, gobernantes que deseaban racionalizar las instituciones y uniformar el régimen de los virreinatos americanos hasta el punto de superimponer en ellos sobre las venerables estructuras administrativas de la casa de Austria las nuevas intendencias y su mayor eficacia, eficacia que hubo de originar numerosas perturbaciones.

En efecto, a las tradicionales exacciones de los corregidores vino a añadirse en el siglo XVIII la reorganización y el aumento de los impuestos y su más eficiente cobranza, lo cual ocasionó varias rebeliones, algunas de ellas encabezadas en el virreinato peruano por indios de auténtica o supuesta sangre imperial inca.

Asỉ, por ejemplo, Juan Bélez de Córdoba en Oruro y 1739 habìa preparado una insurrección, abortada antes de estallar, siendo ejecutado su jefe. En el manifiesto de agravios que éste había redactado se decia: "Hallándose en la presente y entre nosotros uno de la Sangre Real de nuestros Incas del Gran Cuzco en quinto grado de parentesco y con el deseo de restaurar lo propio y volver a establecer esta monarquía, se suplica a los criollos y a los caciques y a todos los naturales le den la mano para esta heroica acción de restaurar lo propio y libertar la patria purgándola de la tiranía de los Guampos que nos consumen 
y cada dỉa va a más nuestra ruina."11 ¿Con la palabra patria querìa Bélez indicar Oruro, Charcas, la extensión de la antigua monarquía inca o América?

En los años de 1780, durante la gran rebelión de José Gabriel Condorcarqui, que tomó el nombre de Túpac Amaru, el concepto de que todos los nacidos en las tierras del antiguo imperio inca eran compatriotas está claramente expresado en los documentos. Así, en un manifiesto a los moradores de la provincia de Chichas, de 23 de diciembre de 1780, Túpac Amaru decìa "haber tomado por acá aquellas medidas que han sido conducentes al amparo, protección y conservación de los españoles criollos, de los mestizos, zambos e indios, y su tranquilidad, por ser todos paisanos y compatriotas, como nacidos en nuestras tierras, y de un mismo origen de los naturales, y el haber padecido todos igualmente dichas opresiones y tiranias de los europeos." 12 El significado de paisanos y compatriotas era el de gente nacida en el mismo lugar, provincia, reino o país, gente que compartia una común patria, y esta patria común en este texto es el territorio del renaciente estado inca de Túpac Amaru. Sabido es que éste habìa leído los Comentarios Reales. ${ }^{13} \mathrm{La}$ frase que al principio citamos en la que Garcilaso llamaba patria "a todo el imperio que fue de los incas," empieza pues a adquirir realidad política en la tentativa de Condorcarqui en el siglo XVIII. No es de extrañar, por lo tanto, que la Corona ordenara se recogieran discretamente en América los ejemplares de aquel libro. 14

Es de observar que a partir de estas fechas la idea del Perú como la patria alterna con el concepto de patria como la ciudad nativa y con el concepto de una patria general americana.

El mejor de los varios periódicos publicados en Lima a fines del mismo siglo XVIII, el Mercurio Peruano, fue según su Prospecto (1790) la obra de "unos hombres estudiosos y verdaderamente amantes de la Patria." 15 Lo fue, en efecto, de un grupo de caballeros que habian organizado primero una tertulia literaria y luego una "Sociedad de Amantes del Paǔs" a imitación de las Sociedades de Amigos del Paǐs, de la Penỉnsula. Si, a veces, bajo su pluma hallamos el nombre de la ciudad nativa, Lima, como el de su patria, mucho más a menudo por patria en el Mercurio se entiende el pais, el Reino del Perú: "las noticias de este Reino... serán noticias que emplearemos ... con un gusto igual al que conceptuamos en un público como éste, tan amante de su Patria y tan deseoso de ilustrarla" (Prospecto). Cuando el Reverendo Padre Fray Antonio Olavarrieta, en su Semanario Crítico, atacó con poco franciscana intemperancia a 
los editores del Mercurio, éstos replicaron que en alguna otra ocasión vindicarían a "nuestro Perú" contra los sarcasmos de su atacante porque hacerlo en aquella primera justificación "hubiera sido profanar el dulce nombre de nuestra Patria, mezclándolo con el del Semanario Crítico, de su autor y de sus asuntos" (MP, No 50, 23-VI1791). No cabe duda, "nuestro Perú" es "el dulce nombre de nuestra Patria." Pudiera multiplicarse el número de citas de tal uso de la palabra en esta publicación.

Por otra parte, en otros momentos, los editores del Mercurio, al reseñar por ejemplo el Papel Periódico, de Santa Fe de Bogotá, se felicitan por "la rapidez con que se va propagando en diversas partes de nuestro continente ese espíritu patriótico que dirige nuestras operaciones" (MP No 87, 3-XI-1791). En esta frase parecen referirse a un espiritu patriótico no ya solamente peruano sino americano.

Por los mismos años, en el extranjero, encontramos a un peruano que, desde la doble perspectiva de Europa y del destierro, propugna sin ambajes el principio de una patria general americana que debiera ser independiente de España. Juan Pablo Viscardo (1748-1798), uno de los jesuitas expulsados de los dominios españoles en 1767, en una carta publicada después de su muerte, Lettre aux Espagnols-Américains par un de leurs compatriotes. Vincet Amor Patriae. L'Amour de la Patrie l'emportera (Filadelfia [i.e., Londres], 1799), más tarde impresa también en castellano, Carta derijida a los Españoles Americanos por Uno de sus compatriotas (Londres, 1801),16 expresa desde un principio que "el nuevo mundo es nuestra patria" (p. 2), que los descendientes de los españoles en América no conocen "otra patria que ésta" (p. 3), que "es evidente que a nosotros solos pertenece el derecho de ejercerla [su administración] y que solos ['nous seuls,' dice el texto francés] podemos llenar sus funciones, con ventaja reciproca de la patria y de nosotros mismos" (p. 8). Por patria entiende Viscardo a toda América, y repite, "el nuevo mundo, nuestra patria" (p. 33), una patria en la cual "se verá renacer la gloria nacional en un imperio inmenso" (p. 39). La claridad conceptual y expresiva de Viscardo es admirable y es también de admirar el que enlace la idea de una patria continental americana con la de gloria nacional "en un inmenso imperio," lo que parece un anuncio de la anfictiona más tarde soñada por Bolivar.

Llegamos así a los primeros años del siglo XIX. Los ataques ingleses a Buenos Aires en 1806 y 1807 y su repulsa por las fuerzas locales dieron pie a muchos escritos en prosa y verso que en el Perú 
se encuentran impresos principalmente en el periódico limeño la Minerva Peruana. En estos escritos los "fieles americanos" son llamados por "Dios, el Rey, Patria y hacienda, honor y gloria" a defender el "patrio suelo," o son elogiados en la hora de la victoria. ${ }^{17} \mathrm{El}$ patrio suelo es obviamente el suelo americano. El sentido de patria no es tan claro ¿América, España, el imperio español? Poco después la invasión napoleónica de la Penĩnsula ocasionó otras efusiones fidelistas. En ellas las palabras patria y patriotismo aparecen con frecuencia. He visto, por ejemplo, un folleto con el larguisimo título de Colección de papeles patrióticos en que constan los hechos con que la muy noble y leal ciudad de La Paz ha acreditado nuevamente su antiguo celo y amor al Soberano y la Patria en las actuales circunstancias de la Monarquia (Lima, sin fecha, pero de muy a fines de 1808 o comienzos de 1809), 58 págs. En él tampoco está muy claro lo que patria y patriótico significan exactamente. ¿Patriotismo español, España es la patria? ¿Patria y patriotismo americanos y lealtad a la Monarquǐa?

Con la Península invadida por los ejércitos franceses, envuelta al mismo tiempo en una guerra de defensa de su independencia y en una reforma constitucional, y enfrentada a la vez con insurrecciones en Caracas, Buenos Aires y México, nuevos matices aparecen en el uso de patria hasta por los peruanos más fieles a la Corona, Vicente Morales Duárez (1755-1812), diputado por Lima en las Cortes de Cádiz, al defender la igualdad de derecho de representación en Cortes de las provincias americanas y las peninsulares en proporción al número de sus habitantes, declaró que si tal igualdad fuera reconocida se podrĭa entonces decir a los insurgentes americanos: "Hermanos, deponed las armas y las penalidades de una vida nueva, militar y vacilante. Recordad el juramento a la gran Patria, las lecciones pacíficas de vuestros padres y el decoro de vuestros nombres." $18 \mathrm{Al}$ explicar las cualidades que debieran tener los diputados, el mismo Morales Duárez opinaba que para serlo hacia falta tener "talentos, probidad, luces y amor a la Patria" y aunque manifestaba conocer que entre los europeos residentes en América se encontraban las dos primeras calidades (talentos y probidad), "no puedo-añadía-formar el mismo juicio de las otras calidades si se comparan a los criollos," es decir, que éstos eran superiores a aquéllos en "luces y amor a la Patria ... entendiendo por Patria el lugar del nacimiento"; y acababa con esta pregunta, “¿Qué deberá esperar la Patria política de quien no ama a su Patria natural? "19 Comenta don Demetrio Ramos, que ha estudiado bien el pensamiento de Morales, que con estas frases 
contrastaba el diputado limeño a la gran patria, los dominios hispánicos, la Monarquía, con las patrias americanas, haciendo de España, la Madre Patria, una patria más (para los peninsulares) junto a las patrias americanas, dentro de la gran patria común. ${ }^{20}$ Nos encontramos pues aquí con la teoría de la doble patria, la natural y la política. La patria política era, para Morales Duárez, la Monarquía, el Imperio, y la patria natural la provincia o el reino de nacimiento. Para un peruano, para Morales, la patria natural era el Reino del Perú dentro de la Monarquía española. Recordemos de paso que el título del Virrey del Perú era Virrey, Gobernador y Capitán General de los Reinos del Perú, Chile, etc.; e igualmente que en la teorìa no había Rey de España sino Rey de Castilla, León, Aragón, Granada, Navarra, etc. El abogado Morales revertǐa así a la tradición de los Católicos Reyes don Fernando y doña Isabel y de sus descendientes de la casa de Austria, la tradición de la monarquía plural, en la Península y en los dominios de Europa y de Ultramar, cada uno independiente de los demás, unidos en una común lealtad a la persona del Rey.

Este es el principio con el que algunos de los independentistas, los patriotas según se llamaron, justificaron en América su insurrección contra las autoridades españolas. Si casi toda España estaba ocupada por Napoleón y Fernando VII prisionero en Francia, el Rey no podía ejercer su autoridad, quedando por ello anulada también la de los virreyes, capitanes generales y audiencias de las Indias, y las autoridades de la Peninsula (Juntas, Juntas Centrales, Regencias, improvisadas en esos momentos de crisis) no tenían tampoco poder sobre los reinos y provincias de América. Prueba claramente este punto de vista el Catecismo Político-Cristiano dispuesto para la instrucción de los pueblos libres de la América meridional por don José Amor de la Patria (el Dr. Juan Martínez de Rosas, de Santiago de Chile), opúsculo manuscrito que los patriotas circularon de contrabando en Lima en 1810: "Los habitantes y provincias de América sólo han jurado fidelidad a los reyes de España, y sólo eran vasallos y dependientes de los mismos reyes, como lo eran y han sido los habitantes y provincias de la Península. Los habitantes y provincias de América no han jurado fidelidad ni son vasallos o dependientes de los habitantes y provincias de España. Los habitantes y provincias de España no tienen, pues, autoridad, jurisdicción ni mando sobre los habitantes y provincias de América." 21

Hasta personaje tan fidelista como Morales Duárez, que deseaba la libertad pero no la separación, predicaba la existencia de patrias naturales libres dentro de la patria política, la Monarquía, la gran 
patria, en la cual los reinos y provincias de América fueran libres e iguales con los reinos y provincias de la Penĭnsula. Hombres menos moderados, menos tradicionalistas y menos legalistas que él iban a dar un paso más allá y proclamar la necesidad de patrias libres en estados separados, independientes.

En Lima, en el Suplemento a la Introducción del Satélite del Peruano publicada ayer, suplemento de 22 de febrero de 1812 , se decía: "La España libre de franceses es nuestra madre patria; la América es nuestra patria en todo el rigor literal de esta palabra. Ambos dominios, el de España y América no componen ya sino una sola patria para americanos y españoles." Una semana más tarde el periódico en su $\mathrm{N}^{\circ} \mathrm{I}$, de $1^{\circ}$ de marzo de 1812 , p. vii, nota (a), se atrevia a ir más lejos: "Por patria entendemos toda la vasta extensión de ambas Américas... Todos cuantos habitamos el nuevo mundo somos hermanos... dignos de componer una nación. De nuestro seno sólo debemos arrojar y no tener por hermanos a aquellos que se oponen a la felicidad de América; éstos, aquellos que desean continúe en ella el antiguo gobierno colonial." No es de extrañar que el Virrey Abascal pronto considerara incendiario y subversivo a El Satélite del Peruano.

Pronto hasta en el periódico oficial del virreinato se desliza la palabra patria aplicada a la insurgencia; por ejemplo, en la Adición a la Gaceta [del Gobierno de Lima] No 100, de 24 de noviembre de 1813 , se reseñan los solemnes funerales celebrados en el convento de Santo Domingo de la capital "por los que perdieron la vida en defensa del Rey y de la Nación y por los ilusos del ejército de la Patria," es decir, los ilusos patriotas, los independentistas.

El fuego de amor de patria, el patriotismo, era mantenido e inflamado por una serie de citas de escritos peninsulares del período liberal anterior al retorno a España de su cautiverio francés del "deseado" Fernando VII, textos que exaltaban el patriotismo español y el amor de la independencia en la lucha contra el invasor. Aparecian en esos escritos frases como las siguientes, reimpresas en $E l$ Investigador, de Lima, II, No 77, del 15 de setiembre de 1814: "No podemos negarnos el placer de insertar algunos versos [de La Viuda de Padilla, tragedia de don Francisco Martínez de la Rosa, representada en Madrid el 29 de marzo] dignos seguramente de ser retenidos en la memoria, no sólo como muestra de poesía, sino también de vigor en los sentimientos de libertad, independencia y amor a la patria," artículo que acababa en un éxtasis exclamatorio: "iAmor a la patria! ¡Sagrada libertad! Independencia, don del cielo...” 
Cualquier lector limeño a ello inclinado podía transponer esas expresiones referentes a España a una referencia peruana: Patria, libertad, independencia.

Después de la proclamación de la del Perú el 28 de julio de 1821 pero antes de su triunfo definitivo en Ayacucho el 9 de diciembre de 1824, durante los años de guerra contra los ejércitos realistas, numerosas efusiones fueron publicadas, en prosa y en verso, en hojas sueltas, folletos y periódicos. El Perú es la patria en muchos de ellos pero en muchos otros la patria es América, el patriotismo es un patriotismo americano, no local o regnícola sino continental. Creo que la base de esta idea de una patria americana se halle en la conceptualización setecentista, ejemplificada por Viscardo y aun por Llano Zapata, apoyada vigorosamente en el hecho de que el ejército libertador era en verdad un ejército americano, compuesto de argentinos, chilenos y peruanos, a las órdenes de San Martín primero, con la adición de venezolanos, colombianos y ecuatorianos después, bajo el mando de Bolívar. Muchúsimas citas pudieran aducirse para demostrarlo: "A la voz de la América unida / De sus hijos se inflama el valor" o "Desde el dỉa que en este hemisferio / De la Patria la aurora brilló," por ejemplo. 22 Su objeto era, naturalmente, "exaltar más y más el patriotismo de los americanos." 23

En algunas ocasiones y en contraste con esa patria continental el viejo sentido de la ciudad como la patria sigue presente. Uno de los más prolíficos versificadores de esos años, Felipe Lledías, en una grandilocuente oda a la reunión en la capital del primer Congreso constituyente del Perú exclamaba en honor de la ciudad: "A qué grado de gloria / te ves engrandecida / ¡Oh venturosa patria! / ¡Oh bienhadada Lima!" 24

Para cerrar esta reseña histórica de patria en el Perú anterior a 1824 quisiera mencionar un manuscrito existente en la Biblioteca Nacional, de Lima. Es un proyecto de ley propuesto al Congreso constituyente por don Mariano José de Arce (1781-1851), diputado por la ciudad de Arequipa, quien cuando la sublevación de Mateo García Pumacahua y ocupación de la ciudad intervino en el cabildo abierto del 12 de noviembre de 1814 en favor de la independencia del Perú lo mismo que en un sermón que pronunció el dỉa siguiente. Arce siguió la suerte de esa insurrección hasta su derrota en Umachiri o Ayaviri, y más tarde fue firmante del Acta de Indepencia en Lima el 28 de julio de 1821. El proyecto de ley va fechado en Lima el 20 de diciembre de 1823 , cuando acababa de recibirse la noticia de una nueva invasión de España, esta vez por los Cien Mil Hijos de San Luis, 
el ejército de Luis XVIII como agente de la Santa Alianza, para derrocar el régimen constitucional impuesto a Fernando VII por el pronunciamiento de Riego y Quiroga en las Cabezas de San Juan y para restablecer al Rey en su trono como monarca absoluto. Dice el artículo primero: "El Congreso peruano a vista de las últimas no[ti] cias de Europa, declara por ciudadanos del Perú con opción a todos los empleos a los liberales de España, que manteniéndose firmes contra todo poder absoluto y contra la Santa Alianza quieran emigrar a esta patria de la libertad." 25

No olvidemos que esta propuesta, que no prosperó porque no podía prosperar en aquellas circunstancias, se hacia en momentos en que poderosos ejércitos del Rey operaban todavía en el Perú y cuando las batallas de Junín $\mathrm{y}$. Ayacucho no habían sido todavía libradas y ganadas por los patriotas. 26

El proceso de auto-identificación del Perú y de los peruanos como identidades autónomas empezado en el siglo XVI alcanzó su pleno fruto a comienzos del XIX. El concepto del pueblo o la ciudad nativa como la patria sobrevivía pero subordinado al concepto más amplio de la patria como el país de nacimiento, el Perú, y con una visión aun más amplia de ella, la de una patria continental, América. En la mente idealista de Mariano José de Arce llegó a extenderse el concepto hacia un sentido de solidaridad con todos los hombres amantes de la libertad: el Perú, para él, era no sólo una patria para sus hijos sino una patria para todos los liberales, una patria de la libertad.

$$
* * * * *
$$

Atendamos ahora a la palabra y la idea de nación. Al hacerlo pasamos del ambiente afectivo que en cualquiera de sus acepciones conlleva patria al examen de la historia peruana de otra palabra, nación, que partiendo de su sentido etimológico y cálido de nacimiento habrá de llegar a un significado moderno y abstracto, el de nación-estado o estado nacional, término de texto de ciencia política que no por ello ha dejado de remover pasiones. El examen de tal deslizamiento semántico en el virreinato peruano es instructivo, tanto histórica como sicológicamente.

Desde los primeros tiempos de la conquista del Perú hallamos en su territorio todos los usos de nación corrientes en el castellano de la época. Significaba primariamente nacimiento, raza, casta, origen. Así en el Libro del Cabildo de la Ciudad de San Juan de la Frontera de Guamanga y en 1540 se ocupaban los regidores de "los puercos e 
puercas o su nación."27 Significaba igualmente origen en cierta provincia, región o reino, como en un texto de 1569 según el cual Valdivia pobló el reino de Chile "destas dos naciones [extremeños y andaluces]."28 Significaba, en fin, los pueblos no cristianos, los paganos, como en el Inca Garcilaso de la Vega, "Otros muchos indios hubo de diversas naciones en aquella primera edad, que escogieron sus dioses con alguna más consideración," o bien, "Otras naciones hubo... que no tuvieron ni tienen inclinación a adorar cosa alguna alta ni baja... sino que en todo vivian y viven hoy como bestias $\mathrm{y}$ peores..." (CR, I, $\mathrm{x})$.

Lo que interesa, sin embargo, es averiguar de qué modo y cuándo nación se refiere al Perú como diferente de la nación española. Garcilaso nos dio una primera posible indicación de una patria inca o quizás peruana. ¿Cómo usa la palabra nación en sus obras históricas sobre el Perú? Generalmente para indicar tribus o conjunto de tribus. Declara, por ejemplo, que su intención "era dividir los tiempos, las edades y las provincias, para que se entendieran mejor las costumbres que cada nación tenìa" ( $C R$, I, xii) o bien escribe que, "A semejanza de las fábulas que hemos dicho de los Incas, inventan las demás naciones del Perú otra infinidad de ellas del origen y principio de sus primeros padres" (CR, I, xix), y asì en muchos otros pasajes (I, ix; I, x; I, xii; I, xiv, p. ej.). Garcilaso no usa, pues, nación con el propósito de identificar la totalidad del imperio inca o la totalidad del Perú como una entidad o identidad nacional, ciertamente no en el sentido latino, hallado entre otros en Cicerón, "eruditissima illa Graecorum natio" (De Oratore, II, iv), corriente también en el castellano de la época, "nación alemana y itálica y francesa," documentado en el Universal Vocabulario, de Alfonso de Palencia, de 1490.29

El significado de nación como raza o casta es el prevalente en el virreinato peruano. Será ello debido al carácter multirracial de su población, constituida sobre la base de la pre-existente población india, la nueva población española conquistadora e inmigrante, la adición de negros, esclavos y horros, y algunos otros, cuantitativamente menos significantes, elementos étnicos. Tal situación se reflejaba hasta en los libros registros de sacramentos administrados por la Iglesia que, en las Indias, los mantenía distintos de "españoles" (que incluỉan a los peninsulares, los criollos y los mestizos hispanizados) y de "naturales" (es decir, los indios), y a veces de otras "castas." La misma distinción se observaba en los frecuentes censos y recuentos de población, de propósito esencialmente fiscal puesto que los diferentes grupos pagaban diferentes impuestos. Todo ello debió 
tender a mantener separada la identidad de las naciones de españoles y naturales y ser causa de que el significado de nación se mantuviera estrechamente enlazado al de casta.

Mencioné antes al cura párroco de Ticsán, gran defensor de los indios, en quien creo percibir un claro descendiente del pensamiento lascasiano, Francisco Rodrĭguez Fernández, que en el manuscrito de su Pecado original; Exhortación previa a los reinos de las Indias ... (1696), se proclama criollo de pura cepa española. A veces usa nación y naciones en el sentido biblico de pueblos paganos: "Naciones hay de gentiles innumerables y dilatadísimas a los costados de estos reinos," que debieran catequizarse, dice en un sermón a la Audiencia de Quito, 1684.30 En el mismo sermón denuncia los obrajes y otros trabajos forzosos a que los indios estaban sometidos y, hablando a una congregación de españoles (es decir, de peninsulares, criollos y mestizos), usó también la palabra nación para distinguir las naciones de españoles y de indios o naturales: "Asî [les agradecéis a los indios] el haber dilatado vuestros reinos y enriquecido vuestra nación sobre todas?" (p. 308). En el mismo libros se encuentran los términos nacionalidad y espiritu nacional empleados para caracterizar el antagonismo entre peninsulares y criollos y, subsidiariamente, entre ambos y los indios. Todo ello lo deplora el Padre Rodríguez calificándolo de "materia de la infernal nacionalidad por estos reinos"; de nuevo, nacionalidad como casta. En su opinión, "toda el alma, ser y vida del espíritu nacional en este Paraǐso no tiene otro centro, otra raíz ni otro origen (por más razones con que lo pretexten, colores con que lo embocen y congruencias con que lo autoricen) que ambiciones por codicia y codicia por ambiciones"' ( $p .383$ ), codicia que es a su modo de ver el pecado original del paraiso americano, la serpiente de la codicia que "aquil profesa, autorizada, consagrada y colocada en trono de veneración la nacionalidad en Indias" (p. 382). Los remedios contra este mal, como contra todos los males políticos, los habia de dar el Rey inspirado en la fe católica, consubstancial con el imperio.

Repetidamente el Padre Rodrĭguez Fernández abomina de "la infernal nacionalidad" y usa este término para significar la división de castas. Es tentador ver aquí en nacionalidad y espiritu nacional el embrión de un sentido de nación a la moderna, pero creo que el contexto prueba que nuestro buen cura habla del sentimiento de casta.

La mayor parte de los criollos peruanos continúa, y en fechas mucho más tardǐas que las de Rodríguez Fernández, hablando de su nación como la nación española o, más precisamente, la nación o 
casta de los españoles. Citaré de nuevo al Doctor Peralta en su Lima inexpugnable (1740). Cuando se refiere a los peligros ocasionados por la guerra con Inglaterra señala la experiencia "que ha tenido nuestra nación en los propugnáculos de Portobelo y Sagre."31 "Nuestra nación" es aquí la nación española a la que el criollo Peralta pertenecía como miembro de la casta de españoles en Indias.

Lo mismo es verdad de otro criollo peruano, Llano Zapata, quien expresa su indignación contra los autores que desacreditan la conquista y el imperio español de América. Le indignaban particularmente los escritos de Fray Bartolomé de las Casas. Lamentaba Llano Zapata en 1761 que de ellos se valiera "la envidia [extranjera] para morder a nuestra nación, que tanto ha trabajado y trabaja en cultivar la de los indios."32 Para Llano esos autores, tanto extranjeros como españoles y en particular Las Casas (aunque no lo nombra), "ocultando bajo el velo de la caridad una supersticiosa hipocresía, en vez de historia esparcieron quimeras, y en lugar de noticias derramaron libelos, que afrentosamente nos calumnian" (p. 2). "Nuestra nación" es claramente la nación española, la casta española, en contraste con "la de los indios," la nación o casta india.

Hasta don Joseph Baquíjano, Catedrático de Vǐspera de Leyes de la Universidad de San Marcos y Fiscal Protector de los naturales del distrito de la Real Audiencia de Lima, en su Elogio del Virrey Jáuregui (1781), habla de Fray Benito Feijoo, español peninsular, el padre de la Ilustración hispánica, como de "una pluma honor del siglo y de la Nación," vale decir, de la nación española o de los españoles. 33

El gran rebelde Túpac Amaru usó frecuentemente en sus escritos nación y naciones en su significado de casta. En carta al Obispo del Cuzco, el 12 de diciembre de 1780, protestaba contra las exacciones de los corregidores y contra "más gabelas que se inspeccionan a las miserables puertas de los fieles vasallos de mi nación, propagándolas con inexorabilidad un segundo Pizarro en la tirania [el Visitador Areche], que no sólo grava a mi nación sino aun a las demás naciones." Los fieles vasallos del Rey eran "de mi nación," esto es indios; "las demás naciones" eran las otras castas. En otra carta del 3 de enero de 1781, dirigida al Cabildo de la ciudad del Cuzco, Túpac Amaru proponía que se suprimieran los corregidores y "que en cada provincia haya un alcalde mayor de la misma nación indiana ..." 34 Incluso la Corona usaba nación en igual sentido en escritos dirigidos a América; asǐ en una Real Orden reservada, de 9 de mayo de 1790, sobre caciques y su sucesión, al referirse a la rebelión tupacamarista aludía a "la ilusa nación de los indios." 35 
Las mismas acepciones ligadas al concepto de casta se perpetúan en el Mercurio Peruano en el cual hallamos la palabra nación referida a la nación española o de los españoles y también, a veces, en el sentido de tribu al referirse a los indios o a los negros. En el Prospecto (1790) su editor, Jacinto Calero, escribe: "En lo que pertenece a Noticias Públicas tendré siempre presente que más nos interesa saber lo que pasa en nuestra Nación que lo que ocupa al Canadense, al Lapón o al Musulmano. Las Gacetas de nuestra Corte, las Papeletas Públicas y los Boletines privados de la misma serán los materiales de donde se extraerán los pasajes y casos que más puedan interesar nuestra curiosidad y nuestras mismas ocupaciones. Sobre todo merecerán un lugar de predilección las noticias de este Reino."36 En la Corte de Madrid o en el Reino del Perú la Nación, con mayúscula, es pues la nación española. Igualmente en el primer número del periódico, de 2 de enero de 1791, se dice que "Los primeros escritores, entre los nacionales, que trataron del Perú, fueron ... Garcilaso, Herrera, Zárate, Gil González . ...," incluyendo en la lista a un mestizo peruano junto con varios peninsulares, todos escritores nacionales. En otras ocasiones el Mercurio emplea nación para designar a otros grupos raciales de la población colonial. En un artículo en el No 48, de 16 de junio de 1791, por ejemplo, su autor al referirse a las congregaciones religiosas de los negros, explica que éstos pertenecen a varias naciones y que en las elecciones celebradas para designar a los dos caporales de una cofradía se tomaba el voto de "los negros capataces y veinte y cuatros (los llamariamos senadores si no temiéramos profanar este nombre) de cada nación." Del mismo modo hallamos nación empleado para designar las tribus de indios de la Montaña, es decir, de la selva (No 79 , de $1^{\circ}$ de octubre de 1791 , por ejemplo).

El ilustre humanista de la Ilustración peruana, Ignacio de Castro (1732-1792), usa también nación y naciones para referirse a las diversas tribus indias: "El Cuzco, que fue por tantos siglos Corte del Soberano Administrador y Depositario legítimo de las porciones de fuerzas y libertad que tantas Naciones subyugadas confiaron a los Incas gozó esta particular prerrogativa. Siempre dio Leyes."37 "Tantas Naciones subyugadas," las tribus y provincias que los Incas sometieron a su imperio.

Cuando Napoleón invadió a España en 1808, la impresión que se recibe al leer los impresos peruanos es la de que los americanos, igual que los peninsulares, emplearon nación en sus escritos antinapoleónicos con el significado de la nación de los españoles, dondequiera que hubieran nacido, en armas contra el Emperador de los 
franceses. En unos versos (llamémoslos asī) grabados en dos láminas de plata pendientes del balcón de la casa de don Ramón Ballivián, vecino distinguido de $\mathrm{La}$ Paz, se leĭa:

Siempre será imponderable

la constante inclinación

con que clama la Nación

¡Viva Fernando el Amable!

Clame la Nación severa

¡Muera el traidor Napoleón! 38

Cuando los representantes de las provincias y los reinos peninsulares y americanos se personaron en las Cortes, reunidas en Cádiz, el diputado por Lima, Vicente Morales Duárez, dijo el 2 de octubre de 1811 que "los pueblos de la Nación, representados en estas Cortes, no reconocen entre si superioridad ni inferioridad porque son iguales."39 Es el mismo Morales que habia hecho en las Cortes la distinción entre patria natural (en su caso, el Perú) y la patria politica, la gran patria, la Monarquía. Queria, según vimos, patrias libres e iguales dentro de la Monarquía. Nótese ahora que en el texto recién citado habla de pueblos y no de naciones, "los pueblos de la Nación," dice: pueblos, patrias naturales, todos libres e iguales dentro de la Nación. Para Morales Duárez, hombre de leyes, la idea y la palabra nación acababa de ser definida en el decreto de Cortes de 15 de octubre de 1810: "Los dominios españoles de ambos hemisferios forman una misma y sola Monarquía, una misma y sola Nación, y una sola familia, y que, por lo mismo, los naturales que sean originarios de dichos dominios europeos o ultramarinos [frase incluida para satisfacer a ciertos diputados americanos, entre los que se contaba Morales, que querian excluir a los negros de la ciudadania], son iguales en derechos a los de esta Península."40

Ya muy tarde, algunos americanos más audaces que Morales Duárez (quien falleció en Cádiz en 1812 siendo Presidente de las Cortes) dieron en el Perú a la palabra e idea de nación (como lo hicieron con patria) un significado político independentista. Creo que este es el sentido que tiene, por ejemplo, en El Satélite del Peruano, de $1^{\circ}$ de marzo de 1812: "Todos cuantos habitamos el nuevo mundo somos hermanos ... dignos de componer una Nación," frase en que se oye como un eco de la voz de Viscardo.

Resulta notable con todo que nación sea palabra poco frecuente en la literatura de los años de la lucha por la independencia del Perú. 
Patria fue la palabra epónima. Los independentistas se llamaron patriotas; sus ejércitos, los ejércitos de la Patria; su grito de guerra, ¡Viva la Patria!

El examen de los textos aducidos, y de otros semejantes que pudieran también citarse, muestra que la palabra nación no fue en el Perú virreinal un término identificador camino del significado de "nación-estado" o "estado nacional" hasta los últimos momentos de la lucha por la independencia. Ello se debe, a mi entender, a que la palabra iba tradicionalmente unida al sentimiento de casta de la sociedad colonial en la que, según vimos, había una nación española o de los españoles (peninsulares, criollos y mestizos, a pesar de sus divisiones y rivalidades internas) y una nación de los naturales (indios) y aun naciones de negros y de indios selváticos. Una frase del Libertador Bolǐvar en su Carta de Jamaica, de 6 de setiembre de 1815, parece confirmar este sentir: "no somos-escribia-indios ni europeos, sino una especie media entre los legítimos propietarios del país [los indios] y los usurpadores españoles: en suma, siendo nosotros americanos de nacimiento y nuestros derechos los de Europa, tenemos que disputar éstos a los del paĭs . . . asĩ nos hallamos en el caso más extraordinario y complicado."41

$$
* * * * *
$$

La palabra identificadora y la idea correlativa que podian tender un puente entre las varias naciones del Perú, y no sólo del Perú en la América española, sobre una base no de casta u origen étnico sino de lugar de nacimiento eran la palabra y la idea de patria. Asi, hemos visto ir desplazándose su sentido prevalente en el virreinato limeño desde la connotación de la "ciudad nativa" como la patria hacia la del "Reino del Perú" como tal patria y hacia la de una patria continental. En Hispanoamérica, como en Roma al desplomarse el imperio (el sìmil y las palabras son del texto bolivariano) "cada desmembración formó un sistema político, conforme a sus intereses y situación o siguiendo la ambición particular de algunos jefes, familias o corporaciónes,"42 organizándose las viejas divisiones administrativas coloniales en Estados separados. Las varias patrias naturales de que había hablado Morales Duárez pasaron a ser también patrias políticas, repúblicas independientes, con una gran patria ideal, ya no el imperio o la monarquía española, sino América. Cada una de esas patrias naturales y políticas ha tenido que elaborarse, en la edad del nacionalismo, su propia nación, al revés de lo usualmente ocurrido en Europa donde cada nación aspiraba, y alguna todavia aspira, a ser un Estado. Si Herder no hubiera inventado en la Alemania del siglo 
XVIII el nacionalismo romántico o el romanticismo nacionalista, los hispanoamericanos hubieran tenido que inventarlo en el XIX para que veinte patrias llegaran también a ser veinte naciones.

Universidad de California, Berkeley

LUIS MONGUIÓ

* Una primera versión, algo más breve y en inglés, de este trabajo fue presentada como la $18^{\text {a }}$ Bernard Moses Memorial Lecture, en la Universidad de California, Berkeley, el 2 de febrero de 1977.

\section{NOTAS} 243.

1. José Ortega y Gasset, Obras completas, VI, 6a ed. (Madrid, 1964), p.

2. No hará falta recordar, p. ej., los sonetos satîricos mexicanos "Viene de España por el mar salobre," "Minas sin plata, sin verdad mineros" y "Niños soldados, mozos capitanes." Ver Marcelino Menéndez Pelayo, Historia de la poesía hispano-americana, ed. Enrique Sánchez Reyes (Santander, 1948), I, págs. 39-41.

3. The Compact Edition of the Oxford English Dictionary (1971), s.v. "fatherland," "motherland" y "nation."

4. Diccionario de la lengua castellana, IV (Madrid, 1734), p. 644 y V (Madrid, 1737), p. 165.

5. Manuel Lorenzo de Vidaurre, "Plan del Perú" y otros escritos, ed. Alberto Tauro (Lima, 1971), p. 78. Tal uso persiste hasta nuestros tiempos. Escritor tan eminente como Jorge Luis Borges escribe en el prefacio a Fervor de Buenos Aires (1923), "Mi patria, Buenos Aires."

6. Por ej., “¿Cómo assi s'acabaron, i perdieron / tan eróico valor en sólo un día; / i lexos de su patria [Portugal] derribados / no fueron justamente sepultados?" de la "Canción por la pérdida del Rei don Sebastián," de Fernando de Herrera, Poesías, ed. Vicente Garcǐa de Diego (Madrid, 1914), p. 85; y "Hispaniam sibi antiquam patriam esse," Salustio, Fragmenta, apud Servio (Ver Harper's Latin Dictionary, s.p. "patrius" y Septem Linguarum Calepinus ... Editio Sexta emendatior ... (Padua, 1746), II, p. 123, s.v.)

7. Ver José Durand, "El influjo de Garcilaso Inca en Túpac Amaru," COPE, Lima, 2, 5 (1971).

8. Verlo en Juan Pérez de Tudela Bueso, "Ideario de don Francisco Rodriguez Fernández, Párroco criollo en los Andes (1696)," Anuario de Estudios Americanos, Sevilla, 17 (1960), 301-406. Lo citado, en la p. 307.

9. Lima inexpugnable. Discurso hercotectónico o de Defensa por medio de la fortificación de este grande emporio... [Lima, 1740], xlvi págs. Ed. y estudio por Luis Antonio Eguiguren Escudero (Lima, 1966), p. xliii.

10. Ed. Ricardo Palma (Lima, 1904), p. 8.

11. Cit. por Boleslao Lewin, La rebelión de Túpac Amaru y los orígenes de la emancipación americana (Buenos Aires, 1957), págs. 118-119.

12. Ibid., p. 403.

13. Durand, "El influjo de Garcilaso ..." 
14. José Torre Revello, El libro, la imprenta y el periodismo en América durante la dominación española (Buenos Aires, 1940), págs. 73 y clxxxix-cxc.

15. Prospecto del Papel Periódico intitulado Mercurio Peruano (Lima, 1790). Ver el Prospecto (1790) y el Mercurio Peruano (1791-1795) por su ed. original o por la facsimilar (Lima, 1964).

16. Ver Miguel Batllori, S.I., El Abate Viscardo. Historia y mito de la intervención de los jesuitas en la independencia de Hispanoamérica (Caracas, 1953), 334 págs., con reproducciones fotográficas de la Lettre y la Carta.

17. Ver. por ej., Minerva Peruana, Lima, No 36, 26 Setiembre 1806, y Adición a la Minerva, 6 Agosto 1808.

18. Diario de Sesiones, No 107,11 Enero 1811, p. 352, cit. por Demetrio Ramos, "El peruano Morales ejemplo de la complejidad americana de tradición y reforma en las Cortes de Cádiz," Revista de Estudios Políticos, Madrid, No 146 (Marzo-Abril 1966), p. 163.

19. Diario de Sesiones, Tomo III, No 360, 27 Setiembre 1811, págs. 1936-37, cit. por Ramos, "El peruano Morales ... .," p. 187.

20. Ramos, "El peruano Morales ... ," págs. 139-202.

21. Diego Barros Arana, Historia jeneral de Chile, VIII (Santiago de Chile, 1887), p. 103, n. 36 (cfr. págs. 178-186). Cit. también por Bernard Moses, The Intellectual Background of the Revolution in Sauth America, 1810-1824 (New York, 1926), p. 60.

22. Correo Mercantil, Político y Literario, Lima, $N^{\circ} 27,18$ Mayo 1822, p. 4.

23. Ibid., No 29, 4 Junio 1822, p. 4, apud Argos de Buenos Aires.

24. Ibid., $N^{\circ} 55.5$ Octubre 1822 , p. 6. Entrega malnumerada; le corresponde el $N^{\circ} 55$ pero lleva por error el 49. Del propio Lledías es, sin embargo, una oda a "La Libertad," ibid., No 5, 5 Enero 1822, p. 4, en que la patria parece ser para él unas veces Lima y otras América.

25. Biblioteca Nacional del Perú, Lima, Departamento de Investigaciones Bibliográficas, Signatura 1823.-D11876. Sobre Arce ver Guillermo Zagarra Meneses, Arequipa en el paso de la Colonia a la República, $2^{\mathrm{a}}$ ed. (Arequipa, 1973), págs. 201-205.

26. Dos años más tarde en un artículo titulado "Liberales de España" sobre los refugiados en Londres decia La Estrella de Ayacucho, No 16, 25 Junio 1825: "Amigos de la Constitución española y muy liberales eran Quiroga y López Baños y el primero se ofreció en Madrid a venir a América a reducirla a la obediencia del gobierno paternal del Rey Fernando y el segundo fue Ministro de la Guerra ... ¿Quién duda de que todos los liberales de España han sido serviles para la América?" El artículo concluye en el $\mathrm{N}^{\mathrm{O}} 19$, de 16 Julio: “¿No es necesaria toda la nobleza del carácter americano para contener nuestra risa y no burlarnos, pues llegó nuestra hora, de estos emigrados o proscriptos?" Así y todo buen número de liberales españoles pasó a América y algunos alcanzaron en diversas repúblicas altos puestos. Ver sobre esto Vicente Lloréns, Liberales y románticos, $2^{\mathrm{a}}$ ed. (Madrid, 1968) y Luis Monguió, Don José Joaquín de Mora y el Perú del Ochocientos (Berkeley y Madrid, 1967). 
27. Cit. por Peter Boyd-Bowman, Léxico hispanoamericano del siglo XVI (Londres, 1951), p. 614, s.v.

28. Ibid., apud José Toribio Medina, Colección de documentos inéditos para la historia de Chile, $2^{a}$ serie, I (1558-72) (Santiago de Chile, 1959), págs. 209-210.

29. John M. Hill, “Universal vocabulario" de Alfonso de Palencia. Registro de voces españolas internas (Madrid, 1957), p. 127. 362.

30. Ver Pérez de Tudela, "Ideario de don Francisco Rodriguez ...," p.

31. Lima inexpugnable, p. iii.

32. Memorias histórico-críticas-apologéticas ..., p. 2.

33. Elogio del Exelentísimo Señor Don Agustín de Jáuregui, y Aldecoa; Caballero del orden de Santiago, Teniente General de los Reales Exércitos, Virrey, Gobernador, y Capitán General de los Reynos del Perú, Chile Ec Pronunciado en el Recibimiento que como a su Vice-patrón, le hizo la Real Universidad de S. Marcos el día XXVII de Agosto del año de M.DCC.LXXXI . . ([Lima, $1781]$ ), p. 74.

34. Lewin, La rebelión de Túpac Amaru...., págs. 460-61 y 465, respectivamente.

35. Ibid., p. 847.

36. Re. Mercurio Peruano ver n. 15 supra.

37. Relación de la fundación de la Real Audiencia del Cuzco en 1788 y de las fiestas con que esta grande y fidelísima Ciudad celebró este honor... (Madrid, 1795), p. 82. Ver también la p. 124.

38. Colección de los papeles patrióticos ... descrita anteriormente en el texto, págs. 45-46.

39. Diario de Sesiones, III, No 365,2 Octubre 1811, p. 1974, cit. por Ramos, "El peruano Morales ...," p. 188. Sobre éste ver también Honores patrios consagrados a la tierna memoria del señor Don Vicente Morales y Duárez, Presidente del Agusto Congreso de Cortes, por el Excmo. Cabildo de esta Capital de Lima... y Oración fúnebre del señor Don Vicente Morales Duárez . . que dixo... el Señor Canónigo Magistral D. D. José Manuel Bermúdez, ambos (Lima, 1812), lii \& 52 págs., respectivamente.

40. Ramos, "El peruano Morales..." p. 158. De la exclusión de los negros se protesta en un opúsculo, firmado "M.L.," y titulado Consideraciones Filosófico-Políticas sobre el artículo 22 cap 4 tít. 2 del Proyecto de Constitución. Las comunica un Español del Perú al Sr. D. Francisco Salazar Diputado de la Capital de aquel Virreinato (Cádiz, 1811), 36 págs. Recela su autor "que aun nos fascinan unos prejuicios muy propios del presuntuoso amor a nuestra casta" ( $p$. 4); protesta de que el propuesto arto 22 sólo admita a los negros a la ciudadanìa por virtud y merecimientos con una serie de condiciones y apunta que esto es incompatible con el arte que requiere de los españoles "ser justos y benéficos." "No lo seremos-continúa-si los libertos, o al menos sus hijos ingenuos, no se declaran ciudadanos españoles como los originarios de nuestros dominios en ambos mundos."

41. Simón Bolǐvar, Carta de Jamaica. Ed. conmemorativa del Sesquicente-. nario de la carta de Jamaica ... (Caracas, 1965), págs. 22-23.

42. Ibid., p. 22. 